\title{
BMJ Open How do general practitioners manage patients with cancer symptoms? A video-vignette study
}

\author{
Moyez Jiwa, ${ }^{1}$ Xingqiong Meng, ${ }^{2}$ Carolyn O'Shea, ${ }^{3}$ Parker Magin, ${ }^{4}$ Ann Dadich, ${ }^{5}$ \\ Vinita Pillai ${ }^{6}$
}

To cite: Jiwa M, Meng $X$, O'Shea C, et al. How do general practitioners manage patients with cancer symptoms? A video-vignette study. BMJ Open 2015;5: e008525. doi:10.1136/ bmjopen-2015-008525

- Prepublication history for this paper is available online. To view these files please visit the journal online (http://dx.doi.org/10.1136/ bmjopen-2015-008525).

Received 17 April 2015 Revised 21 July 2015 Accepted 24 July 2015

\section{(1) crossmatk}

${ }^{1}$ Melbourne Clinical School, School of Medicine Sydney, University of Notre Dame, Werribee, Victoria, Australia ${ }^{2}$ School of Medicine, Flinders University, Adelaide, South Australia, Australia

${ }^{3}$ Victorian Metropolitan Alliance, Hawthorn, Victoria, Australia

${ }^{4}$ Discipline of General Practice, University of Newcastle, Callaghan, New South Wales, Australia

${ }^{5}$ School of Business, University of Western Sydney, Parramatta, New South Wales, Australia

${ }^{6}$ Department of Medical Education, Curtin University, Perth, Western Australia, Australia

Correspondence to Professor Moyez Jiwa; moyez.jiwa@nd.edu.au

\section{ABSTRACT}

Objectives: Determine how general practitioners (GPs) manage patients with cancer symptoms.

Design: GPs reviewed 24 video-vignettes and case notes on patients with cancer symptoms and indicated whether they would refer the patient and/or prescribe medication, and/or undertake further investigation. According to available guidelines, all cases warranted a referral to a specialist or further investigations.

Setting: Australian primary care sector.

Participants: 102 practising GPs participated in this study, including trainees.

Interventions: The research was part of a larger randomised controlled trial testing a referral pro forma; however, this paper reports on management decisions made throughout the study.

Primary and secondary outcome measures: This paper reports on how the participants would manage the patients depicted in each vignette.

Results: In more than one-in-eight cases, the patient was not investigated or referred. Patient management varied significantly by cancer type $(p<0.001)$. For two key reasons, colorectal cancer was the chosen referent category. First, it represents a prevalent type of cancer. Second, in this study, colorectal cancer symptoms were managed in a similar proportion of options-that is, prescription, referral or investigation. Compared with vignettes featuring colorectal cancer participants were less likely to manage breast, bladder, endometrial, and lung cancers with a 'prescription only' or 'referral only' option. They were less likely to manage prostate cancer with a 'prescription only', yet more likely to manage it with a 'referral with investigation'. With regard to pancreatic and cervical cancers, participants were more likely to manage these with a 'referral only' or a 'referral with investigation'.

Conclusions: Some patients may receive a delayed cancer diagnosis, even when they present with typical cancer symptoms to a GP who can access relevant diagnostic tests.

Trial registration number: ACTRN12611000760976.

\section{INTRODUCTION}

Australians who experience symptoms do not have direct access to specialists, but are required to consult a general practitioner

\section{Strengths and limitations of this study}

- Many Western nations position general practitioners (GPs) as the gatekeeper to specialist services, while enabling their access to diagnostic tests. This can be particularly helpful in cancer care.

- GPs were invited to review video-vignettes of patients with possible cancer symptoms and decide how they would manage these patients.

- There was limited evidence that appropriate tests would be ordered, and a significant proportion of high-risk cases were not immediately referred for further investigation or specialist opinion.

- The study design did not examine the reasons for the GP decisions.

- Some patients may receive a delayed cancer diagnosis, even when they present with typical cancer symptoms to a GP who can access relevant diagnostic tests.

(GP) or attend an emergency department. ${ }^{1}$ Akin to other health systems, ${ }^{2}$ the Australian health system positions GPs as the gatekeeper to specialist services. ${ }^{3}$

In Australia, GPs can refer for a range of tests including ultrasounds and CT scans and, with specific indications, some MRI. In some Australian jurisdictions, GPs can also directly refer for gastroscopy and colonoscopy. This represents a greater range of tests relative to other health systems, like in the UK. ${ }^{4}$

GP access to diagnostic tests is particularly helpful in cancer care. ${ }^{5}$ It can optimise the timely receipt of appropriate treatment and as such reduce, if not avert, the personal, social and economic costs of cancer. ${ }^{6-8}$ Given the complexity of health systems, it can be difficult (if not impossible) to isolate definitive causal relationships between GP diagnostic tests and cancer outcomes. ${ }^{9} 10$ However, GP access to diagnostic tests is likely to help identify those patients who require urgent care. $^{11}$ 
As part of a larger pre-post, randomised control trial of an interactive online referral pro forma, ${ }^{12}$ the review of data reported here focused on how Australian GPs manage patients with cancer symptoms. The intervention tested in the original trial did not aim to guide GP referral, investigation or prescribing practices-as such, its focus is not germane to the focus of this review, which encompasses data from both phases. ${ }^{12}$

\section{METHODS}

Following clearance from the relevant ethics committee, the research team recruited GPs in seven Australian states and territories to participate in this study via email, newsletters and personal contact. Recruitment was facilitated by primary care networks, university departments, research networks and personal contacts. GPs were eligible to participate if they were currently in practice, including registrars (or vocational trainees), and had internet access. As such, the exact number of GPs who were aware of the project cannot be ascertained.

Participants were invited to consider the symptoms of patients presented as video-vignettes and to determine how they would manage the patient. This was conducted in two phases-before the participants were provided with an interactive referral pro forma, and afterwards. The pro forma aimed to improve the quantity and quality of patient information communicated between primary and secondary care clinicians. The focus of this paper, however, is to determine how GPs respond to patients with different cancer symptoms, regardless of whether this was before or after using the pro forma.

Guided by the 2005 referral guidelines for suspected cancer of the National Institute for Health and Clinical Excellence (NICE) ${ }^{13} 24$ video-vignettes were developed by six GPs, four videos for each of six cancer types (table 1). These guidelines were selected as they indicate the need for specialist referral based on specific highrisk presentations; furthermore, at the time of the study, no equivalent Australia-wide guidelines were available for all cancer types. The video-vignettes comprised a 4 min video monologue delivered by an actor-patient accompanied by case notes containing the patient's medical history, current medication, allergies and previous consultations. The video included an off-camera commentary by an actor-doctor describing clinical signs to be found at this visit.

After accessing a secured research website, participants: provided demographic information; received the

Table 1 Cancer cases

\begin{tabular}{|c|c|}
\hline Cancer type & Case details \\
\hline Bladder & 76-year-old woman with asymptomatic frank haematuria \\
\hline Breast & 35-year-old with asymptomatic, firm breast lump and skin dimpling \\
\hline Breast & 69-year-old with skin changes consistent with Paget's disease of the breast \\
\hline Cervical & 34-year-old with CIN 2 \\
\hline Colorectal & 60-year-old with unexplained iron deficiency anaemia, abdominal pain and right iliac fossa abdominal mass \\
\hline Endometrial & 65-year-old with PMB \\
\hline Lung & 58-year-old lifelong smoker with haemoptysis, breathlessness and weight loss \\
\hline Oesophageal & 66-year-old with $10 \mathrm{~kg}$ weight loss and dysphagia for solids \\
\hline Pancreatic & $\begin{array}{l}\text { 57-year-old with } 5 \mathrm{~kg} \text { weight loss, jaundice, generalised pruritus and pancreatic mass on abdominal } \\
\text { ultrasound scan }\end{array}$ \\
\hline Prostate & 55-year-old with a PSA of 22, urinary frequency, haematuria, hesitancy and terminal dribbling \\
\hline Lung & 49-year-old smoker with cervical lymphadenopathy, haemoptysis and a $2 \mathrm{~cm}$ mass on chest $X$-ray \\
\hline Colorectal & 65-year-old with rectal bleeding, diarrhoea, fatigue and rectal mass \\
\hline Bladder & 65-year-old man with frank asymptomatic haematuria \\
\hline Breast & 38-year-old with a 3-month history of breast lump, dimpling of skin and axillary lymphadenopathy \\
\hline Breast & 71-year-old with a breast lump and peau d'orange \\
\hline Cervical & 36-year-old with CIN 2 and postcoital bleeding \\
\hline Colorectal & $\begin{array}{l}\text { 62-year-old man with a 2-month history of constipation, abdominal pain, hepatomegaly and iron deficiency } \\
\text { anaemia }\end{array}$ \\
\hline Endometrial & 62-year-old with several episodes of PMB \\
\hline Lung & 60-year-old woman with cough, dyspnoea, weight loss, hoarseness, pleural effusion and clubbing \\
\hline Lung & 61-year-old man with cough, suspicious lesion on chest X-ray and haemoptysis \\
\hline Oesophageal & 69-year-old man with dysphagia for solids, weight loss, dyspepsia and fatigue \\
\hline Pancreatic & $\begin{array}{l}\text { 60-year-old man with abdominal pain, chronic pancreatitis, weight loss, jaundice and pancreatic mass on } \\
\text { abdominal ultrasound scan }\end{array}$ \\
\hline Prostate & $\begin{array}{l}\text { 70-year-old abnormal digital rectal examination findings, PSA of } 25 \text {, chronic retention, prostatism and low back } \\
\text { pain }\end{array}$ \\
\hline Colorectal & $\begin{array}{l}\text { 63-year-old woman with altered bowel habits, iron deficiency anaemia, abdominal pain, weight loss and rectal } \\
\text { bleeding }\end{array}$ \\
\hline
\end{tabular}


case notes of each patient; viewed the video-vignette of the consultation once and received examination findings. Participants then chose to: (1) prescribe medication; (2) order diagnostic tests and/or (3) refer the patient to a specialist. Participants documented the prescription, the test, and/or the referral as they would when consulting a bona fide patient. Each participant viewed and managed 24 video-vignettes.

Participants were recompensed for their participation and could claim continuing medical education points. Progress through the video-vignettes could be tracked online and reminders were issued to those who had not completed the study after 2 weeks of inactivity.

\section{Statistical analysis}

Descriptive statistics (number and percentage) were used to report participants' management of each scenario, preintervention and postintervention. A multinominal logistic model was used to assess the influence of demographic information and specialty on the ways the participants chose to manage the patient, with particular reference to: 'prescription only', 'investigation(s) only', 'referral only' and 'referral with investigation(s)'. 'Investigation only' was selected as the base outcome, and the relative risk ratio of 'prescription only', 'referral only' and 'referral and investigation' are reported. User-defined parsimonious models were constructed in a backward elimination fashion from the full model. The full model included: (1) participants' demographic data-notably age, gender, country of graduation, number of years since graduation, years of GP experience, Fellowship of the Royal Australian college of General Practitioners (FRACGP), clinic remoteness (4 categories: major cities, inner regional, outer regional and remote/very remote), role within their primary practice, patients consulted per week (3 categories: $<100$, 100-149, $\geq 150$ ), direct patient care hours per week (4 categories: <11, 11-20, 21-40, $\geq 41)$, non-English consultation (no and yes), number of GPs within their primary practice, and number of patient sessions per week and (2) cancer type. Only variables with $\mathrm{p}<0.05$ were retained in the final model. The categories of some variables were regrouped as noted, before they were entered into the model, due to their small number. In the regression, preintervention and postintervention data were pooled according to cancer types. Given the lack of independence between participant responses, regression models were adjusted by estimating the cluster effect using the 'vce' option within Stata. $p$ Values of $<0.05$ were considered statistically significant. Stata MP 13.1 (StataCorp, Texas, USA) was used to perform the analysis.

\section{RESULTS}

Between August 2011 and August 2012 (inclusive), 102 GPs were recruited. Participants were mainly from Western Australia (46\%) and Victoria (25\%), with a mean age of 43 years (table 2). On average, the participants had 13 years of GP experience; however, 24\% were trainees. Most participants primarily practised in a capital city or another metropolitan area.

Patient management varied by cancer case. Before the intervention, relatively few participants managed the patient with a 'prescription only' (range $=1.0-10.8 \%$, mean $=2.8 \%$, table 3). After the intervention, more chose to manage the patient with a 'prescription' (9.8$32.6 \%$, mean $=21.5 \%)$ or an 'investigation only' ( range $=25.0-71.7 \%$, mean $=43.5 \%$ ). Of all the demographic data pertaining to the doctors, the only factor that appeared to influence their decisions was the geographical location of their practice $(p<0.001$ of the overall Wald test after regression).

Patient management also varied significantly by cancer type $(p<0.001$ of the overall Wald test, table 4$)$. Colorectal cancer symptoms were managed almost equally across the choice of options with a similar proportion managed with each of the three options. Compared to the management of colorectal cancer symptoms, participants were less likely to manage breast, bladder, endometrial and lung cancer symptoms with a 'prescription' or 'referral only'. They were less likely to manage prostate cancer with a 'prescription only', yet more likely to manage it with a 'referral with investigation'. With regard to pancreatic and cervical cancers, participants were more likely to manage these with a 'referral only' or a 'referral with investigation', relative to the management of colorectal cancer. Compared with those who practised in a major city, participants who practised in a remote or very remote practice were significantly less likely to opt for a 'prescription' or a 'referral only', yet more likely to manage the patient with an 'investigation only' (see table 4). The investigations and treatment options suggested are presented in table 5 .

\section{DISCUSSION}

\section{Findings}

According to the 2005 NICE guidelines, all cases in this study warranted a specialist review within 2 weeks. ${ }^{13}$ The research results suggest that in more than one-in-eight cases, the patient was not investigated or referred, despite symptoms that were highly suggestive of cancer. In some cases, the indication for the drugs prescribed as per table 5 was unclear and in the case of endometrial cancer, the prescription of oestrogen replacement therapy may have actually advanced cancer progression. $^{18}$

Compared to cases presenting with colorectal symptoms, participants were more likely to refer a patient presenting with symptoms of pancreatic, prostate or cervical cancer, with or without further investigation. These cases included relatively more objective signs of pathology sourced from a laboratory and/or radiological report. This suggests that, despite the UK guidelines, 
Table 2 Participant demographics $(n=102)$

\begin{tabular}{|c|c|c|c|}
\hline & \multicolumn{2}{|c|}{ Participants } & \multirow{2}{*}{$\begin{array}{l}\text { National } \\
\text { comparison }\end{array}$} \\
\hline & Mean & SD & \\
\hline Age, years & 43 & 11.8 & $50.5^{\star}$ \\
\hline Years after graduation & 19 & 11.3 & \\
\hline Years as GP & 13 & 11.1 & \\
\hline GPs in primary practice & 8 & 4.1 & \\
\hline \multirow[t]{2}{*}{ GP sessions/week } & 6 & 3.0 & \\
\hline & $\mathbf{N}^{\circ}$ & $\%$ & \\
\hline Male & 58 & 56.9 & $60.9 \% \dagger^{17}$ \\
\hline Graduated in Australia & 73 & 71.6 & $65.9 \% \dagger$ \\
\hline GP registrar & 24 & 23.5 & $3.8 \% \ddagger$ \\
\hline FRACGP & 58 & 56.9 & $56.8 \rrbracket$ \\
\hline Accredited practice & 101 & 99.0 & $88.6 \prod$ \\
\hline \multicolumn{4}{|l|}{ Position } \\
\hline Principal & 21 & 20.6 & \\
\hline Non-principal & 63 & 61.8 & \\
\hline Other & 18 & 17.6 & \\
\hline \multicolumn{4}{|l|}{ State } \\
\hline New South Wales & 13 & 12.7 & $33.1 \% \neq$ \\
\hline Queensland & 7 & 6.8 & $19.5 \% \ddagger$ \\
\hline Victoria & 25 & 24.5 & $25.1 \% \ddagger$ \\
\hline South Australia & 7 & 6.9 & $8.4 \% \ddagger$ \\
\hline Tasmania & 1 & 1.0 & $2.6 \% \ddagger$ \\
\hline Western Australia & 47 & 46.1 & $9.1 \% \ddagger$ \\
\hline Australian Capital Territory & 2 & 2.0 & $1.5 \% \ddagger$ \\
\hline \multicolumn{4}{|l|}{ Region of primary practice } \\
\hline Capital city & 49 & 48.0 & $66.3 \%$ \\
\hline Other metropolitan area & 38 & 37.3 & $7.6 \%$ \\
\hline Large rural area & 5 & 4.9 & $6.7 \%$ \\
\hline Small rural area & 6 & 5.9 & $7.1 \%$ \\
\hline Other rural area & 3 & 2.9 & $10.6 \%$ \\
\hline Remote centre & 1 & 1.0 & $0.6 \%$ \\
\hline \multicolumn{4}{|l|}{ Remoteness of the region } \\
\hline Major city & 73 & 71.6 & $71.5 \% \ddagger$ \\
\hline Inner regional area & 15 & 14.7 & $18.9 \% \ddagger$ \\
\hline Outer regional area & 10 & 9.8 & $7.8 \% \ddagger$ \\
\hline Remote area & 3 & 2.9 & $1.2 \% \ddagger$ \\
\hline Very remote area & 1 & 1.0 & $0.6 \% \ddagger$ \\
\hline \multicolumn{4}{|l|}{ Patients consulted, per week } \\
\hline$<100$ & 49 & 48.0 & \\
\hline $100-149$ & 30 & 29.4 & \\
\hline $150-199$ & 20 & 19.6 & \\
\hline$>199$ & 3 & 3.0 & \\
\hline \multicolumn{4}{|l|}{ Direct patient care, h/week } \\
\hline$<11$ & 11 & 10.8 & $1.2 \%$ \\
\hline $11-20$ & 21 & 20.6 & $12.2 \%$ \\
\hline $21-40$ & 47 & 46.1 & $53 \%$ \\
\hline $41-60$ & 20 & 19.6 & $32.1 \%$ १ \\
\hline$>60$ & 3 & 2.9 & $1.4 \%$ \\
\hline \multicolumn{4}{|c|}{ Non-English patient consultations, \% } \\
\hline 0 & 84 & 82.3 & $72.6 \%$ \\
\hline$<25$ & 17 & 16.7 & $21.7 \%$ \\
\hline $25-50$ & 0 & 0 & $2.9 \%$ \\
\hline$>50$ & 1 & 1.0 & $2.8 \% \rrbracket$ \\
\hline \multicolumn{4}{|c|}{$\begin{array}{l}\text { *Sourced from Britt et al }{ }^{14} \text { and the Australian Institute of Health and Welfare. }{ }^{15} \\
\text { †Sourced from Britt et al. }{ }^{14} \\
\text { †Sourced from General Practice Education and Training Limited. }{ }^{16} \\
\text { §Sourced from the Primary Health Care Research \& Information Service. }{ }^{17} \\
\text { ๆCompared to GPs involved in Britt et al. }{ }^{14}\end{array}$} \\
\hline
\end{tabular}


Table 3 GP management decisions*

\begin{tabular}{|c|c|c|c|c|c|c|c|c|}
\hline \multirow[b]{2}{*}{ Cancer } & \multicolumn{2}{|c|}{$\begin{array}{l}\text { Prescription } \\
\text { only }\end{array}$} & \multicolumn{2}{|c|}{$\begin{array}{l}\text { Investigation(s) } \\
\text { only }\end{array}$} & \multicolumn{2}{|c|}{ Referral only } & \multicolumn{2}{|c|}{$\begin{array}{l}\text { Referred with } \\
\text { investigation(s) }\end{array}$} \\
\hline & $\mathbf{N}^{\circ}$ & $\%$ & $\mathbf{N}^{\circ}$ & $\%$ & $\overline{\mathbf{N}^{\circ}}$ & $\%$ & $\overline{\mathbf{N}^{\circ}}$ & $\%$ \\
\hline \multicolumn{9}{|c|}{ Preintervention ( $n=102)$} \\
\hline Bladder & 1 & 1.0 & 58 & 56.9 & 16 & 15.7 & 27 & 26.5 \\
\hline Breast & 3 & 2.9 & 71 & 69.6 & 15 & 14.7 & 13 & 12.7 \\
\hline Breast & 11 & 10.8 & 53 & 52.0 & 16 & 15.7 & 22 & 21.6 \\
\hline Cervical & 4 & 3.9 & 3 & 2.9 & 72 & 70.6 & 23 & 22.5 \\
\hline Colorectal & 2 & 2.0 & 19 & 18.6 & 66 & 64.7 & 15 & 14.7 \\
\hline Endometrial & 3 & 2.9 & 39 & 38.2 & 33 & 32.4 & 27 & 26.5 \\
\hline Lung & 1 & 1.0 & 58 & 56.9 & 12 & 11.8 & 31 & 30.4 \\
\hline Oesophageal & 1 & 1.0 & 23 & 22.5 & 49 & 48.0 & 29 & 28.4 \\
\hline Pancreatic & 2 & 2.0 & 11 & 10.8 & 55 & 53.9 & 34 & 33.3 \\
\hline Prostate & 1 & 1.0 & 13 & 12.7 & 65 & 63.7 & 23 & 22.5 \\
\hline Total & 29 & 2.8 & 348 & 34.1 & 399 & 39.1 & 244 & 23.9 \\
\hline \multicolumn{9}{|c|}{ Postintervention (n=92) } \\
\hline Lung & 25 & 27.2 & 38 & 41.3 & 18 & 19.6 & 11 & 12.0 \\
\hline Colorectal & 35 & 38.0 & 20 & 21.7 & 30 & 32.6 & 7 & 7.6 \\
\hline Bladder & 15 & 16.3 & 54 & 58.7 & 9 & 9.8 & 14 & 15.2 \\
\hline Breast & 13 & 14.1 & 56 & 60.9 & 8 & 8.7 & 15 & 16.3 \\
\hline Breast & 14 & 15.2 & 57 & 62.0 & 9 & 9.8 & 12 & 13.0 \\
\hline Cervical & 20 & 21.7 & 33 & 35.9 & 19 & 20.7 & 20 & 21.7 \\
\hline Colorectal & 21 & 22.8 & 34 & 37.0 & 21 & 22.8 & 16 & 17.4 \\
\hline Endometrial & 15 & 16.3 & 46 & 50.0 & 12 & 13.0 & 19 & 20.7 \\
\hline Lung & 9 & 9.8 & 66 & 71.7 & 5 & 5.4 & 12 & 13.0 \\
\hline Lung & 18 & 19.6 & 42 & 45.7 & 15 & 16.3 & 17 & 18.5 \\
\hline Oesophageal & 26 & 28.3 & 29 & 31.5 & 18 & 19.6 & 19 & 20.7 \\
\hline Pancreatic & 30 & 32.6 & 23 & 25.0 & 29 & 31.5 & 10 & 10.9 \\
\hline Prostate & 14 & 15.2 & 36 & 39.1 & 16 & 17.4 & 26 & 28.3 \\
\hline Colorectal & 22 & 23.9 & 26 & 28.3 & 22 & 23.9 & 22 & 23.9 \\
\hline Total & 277 & 21.5 & 560 & 43.5 & 231 & 17.9 & 220 & 17.1 \\
\hline
\end{tabular}

${ }^{*}$ Percentages may not total $100 \%$ due to rounding.

Table 4 Factors associated with GP cancer management $(n=2308)$

\begin{tabular}{|c|c|c|c|c|c|c|}
\hline \multirow[b]{2}{*}{ Video } & \multicolumn{2}{|c|}{$\operatorname{rrr}(95 \% \mathrm{Cl})$} & \multicolumn{2}{|c|}{$\operatorname{rrr}(95 \% \mathrm{Cl})$} & \multicolumn{2}{|c|}{$\operatorname{rrr}(95 \% \mathrm{Cl})$} \\
\hline & \multicolumn{2}{|c|}{$\begin{array}{l}\text { Prescription only vs } \\
\text { investigation(s) only }\end{array}$} & \multicolumn{2}{|c|}{$\begin{array}{l}\text { Referral only vs } \\
\text { investigation(s) only }\end{array}$} & \multicolumn{2}{|c|}{$\begin{array}{l}\text { Referral with } \\
\text { investigation(s) vs } \\
\text { investigation(s) only }\end{array}$} \\
\hline \multicolumn{7}{|l|}{ Cancer (colorectal, rrr=1) } \\
\hline Breast & 0.21 & $(0.14 \text { to } 0.32)^{\star \star \star}$ & 0.14 & $(0.09 \text { to } 0.22)^{\star \star \star}$ & 0.42 & $(0.28 \text { to } 0.65)^{\star \star \star}$ \\
\hline Bladder & 0.17 & $(0.10 \text { to } 0.30)^{\star \star \star}$ & 0.16 & $(0.09 \text { to } 0.27)^{\star \star \star}$ & 0.60 & $(0.37 \text { to } 0.95)^{\star}$ \\
\hline Endometrial & 0.26 & $(0.15 \text { to } 0.46)^{\star \star \star}$ & 0.37 & $(0.23 \text { to } 0.60)^{\star \star \star}$ & 0.88 & (0.57 to 1.36$)$ \\
\hline Prostate & 0.38 & $(0.20 \text { to } 0.73)^{* *}$ & 1.18 & $(0.82$ to 1.71$)$ & 1.65 & $(1.05 \text { to } 2.60)^{\star}$ \\
\hline Pancreatic & 1.17 & (0.68 to 2.02 ) & 1.78 & $(1.10 \text { to } 2.86)^{\star}$ & 2.15 & $(1.30 \text { to } 3.56)^{\star \star}$ \\
\hline Cervical & 0.83 & (0.51 to 1.36$)$ & 1.82 & $(1.30 \text { to } 2.54)^{\star * *}$ & 1.98 & $(1.30 \text { to } 3.02)^{\star * *}$ \\
\hline Lung & 0.32 & $(0.21 \text { to } 0.46)^{* \star *}$ & 0.17 & $(0.11 \text { to } 0.26)^{\star \star \star}$ & 0.57 & $(0.39 \text { to } 0.83)^{\star \star}$ \\
\hline Oesophageal & 0.64 & $(0.42 \text { to } 0.99)^{*}$ & 0.92 & (0.63 to 1.34$)$ & 1.52 & $(1.01 \text { to } 2.29)^{\star}$ \\
\hline \multicolumn{7}{|c|}{ Clinic remoteness (major city, rrr=1) } \\
\hline Inner regional & 0.84 & (0.44 to 1.62$)$ & 0.46 & $(0.29 \text { to } 0.73)^{\star * *}$ & 0.82 & (0.38 to 1.75$)$ \\
\hline Outer regional & 0.57 & (0.17 to 1.95$)$ & 1.13 & (0.50 to 2.51$)$ & 1.15 & (0.50 to 2.64$)$ \\
\hline Remote/very remote & 0.05 & $(0.01 \text { to } 0.25)^{\star \star \star}$ & 0.42 & $(0.26 \text { to } 0.67)^{\star \star \star}$ & 0.41 & (0.09 to 1.83$)$ \\
\hline
\end{tabular}


Table 5 Investigations requested and prescriptions per cancer type

\begin{tabular}{|c|c|c|}
\hline Cancer type & Investigations & Prescriptions ordered \\
\hline Breast & $\begin{array}{l}\text { Mammogram, fine-needle biopsy, full blood count, renal function } \\
\text { test, liver function test, ultrasound scan }\end{array}$ & $\begin{array}{l}\text { Antifungals, antibiotic tablets or creams, } \\
\text { steroid creams, antihistamines }\end{array}$ \\
\hline Lung & $\begin{array}{l}\text { CT scan/chest X-ray, ultrasound scan, fine-needle aspiration, } \\
\text { bronchoscopy, spirometry, lung biopsy, full blood count, renal } \\
\text { function test, liver function test, coagulation studies, ferritin, sputum } \\
\text { microscopy and culture/cytology, Mantoux test }\end{array}$ & $\begin{array}{l}\text { Steroid tablets, antibiotics, diuretics, } \\
\text { codeine, steroid inhalers, } \beta \text {-agonist } \\
\text { inhalers }\end{array}$ \\
\hline Prostate & $\begin{array}{l}\text { Urine microscopy and culture, urine cytology, PSA, CT, ultrasound } \\
\text { scan, full blood count, renal function, liver function test, X-ray }\end{array}$ & $\begin{array}{l}\text { Opiates, paracetamol, non-steroidal } \\
\text { anti-inflammatory tablets, } \alpha \text {-blockers, } \\
5 \alpha \text {-reductase enzyme inhibitors }\end{array}$ \\
\hline Bladder & $\begin{array}{l}\text { Urine microscopy and culture, urine cytology, PSA, CT, ultrasound } \\
\text { scan, full blood count, renal function, liver function test, intravenous } \\
\text { pyelogram }\end{array}$ & Nil \\
\hline Colorectal & $\begin{array}{l}\text { Colonoscopy/gastroscopy, CT/ultrasound scan, stool culture and } \\
\text { sensitivity, cytology, faecal occult blood test, full blood count, renal } \\
\text { function test, liver function test, erythrocyte sedimentation rate, iron } \\
\text { studies, lipase, calcium, magnesium, phosphate }\end{array}$ & $\begin{array}{l}\text { Paracetamol, iron supplements, iron } \\
\text { injections, laxatives, antispasmodics, } \\
\text { vitamin C, opiates }\end{array}$ \\
\hline Pancreatic & $\begin{array}{l}\text { Full blood count, renal function test, liver function test, blood } \\
\text { glucose, coagulation profile, amylase, lipase, bilirubin, CT, } \\
\text { ultrasound scan/bone scan }\end{array}$ & $\begin{array}{l}\text { Paracetamol, codeine, opiates, } \\
\text { cholestyramine, vitamin } \mathrm{B}_{12} \\
\text { proton-pump inhibitors }\end{array}$ \\
\hline Oesophageal & $\begin{array}{l}\text { Barium swallow/chest X-ray, CT/ultrasound scan, gastroscopy, full } \\
\text { blood count, renal function test, liver function test, iron studies, } \\
\text { coagulation studies, urea breath test/Helicobacter pylori serology }\end{array}$ & $\begin{array}{l}\text { Antiemetics, food supplements, } \\
\text { proton-pump inhibitors }\end{array}$ \\
\hline Cervical & $\begin{array}{l}\text { Vaginal swab MCS/Pap smear, human papilloma virus cytology, } \\
\text { urine culture and sensitivity, chlamydia, gonorrhoea PCR, human } \\
\text { immune deficiency virology, hepatitis B, hepatitis C, syphilis } \\
\text { serology, VDRL, full blood count, renal function test, liver function } \\
\text { test, ferritin, ultrasound scan/CT, colposcopy/endoscopy }\end{array}$ & 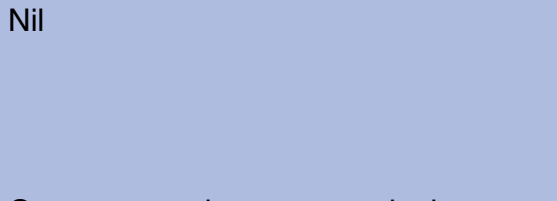 \\
\hline Endometrial & $\begin{array}{l}\text { US pelvic/vaginal, full blood count, renal function test, liver function } \\
\text { test, iron studies, coagulation studies, Pap smear/swab, urine } \\
\text { culture and sensitivity, X-ray, CT, hysteroscopy }\end{array}$ & $\begin{array}{l}\text { Oestrogen replacement vaginal } \\
\text { pessaries }\end{array}$ \\
\hline
\end{tabular}

these participants may have been reticent to refer patients without further investigation-this was particularly the case for breast, bladder, endometrial and lung cancers where the patient presented with signs and symptoms, without confirmatory laboratory tests. Notably, in the case of lung cancer, a suspicious lesion on a chest X-ray did not appear to warrant immediate referral in most cases.

The participants appeared to have different views on how to manage patients with cancer symptoms-and the reason for these opinions could not be gleaned (eg, $\mathrm{X}$-ray for endometrial cancer). This might suggest that the participants collectively recognised both the advantages and disadvantages associated with further investigation. The former may include the efficient use of limited diagnostic and subsequent specialist services. This may be particularly advantageous for patients who do not reside in close proximity to specialist services. This was suggested by the study results, as participants who practised in rural and remote locations were more likely to request further investigation prior to referral; yet research suggests that cancer outcomes in these locations are worse than in metropolitan areas. ${ }^{19}$ The disadvantages associated with locally conducted investigation may include the financial cost to the patient, as well as delayed specialist advice and care. ${ }^{20}$

\section{Strengths and weaknesses of the study}

A key strength of this study is consistency in both the cases reviewed by the participants and the way they reviewed the cases. Furthermore, participants were unaware of the case content before commencing the study. As such, participants did not simply include GPs with a particular interest in cancer care.

However, the study is limited in four key ways. First, it did not enable interaction between the participant and the patient, or the participant and the specialist. Such communication is likely to promote effective patient care. Second, data were not collected on review plans to better understand the participants' perspectives on the case. This may be particularly relevant for the option, 'investigation only', where a subsequent review may help to confirm a diagnosis and lead to referral. Third, since the participants differed from GPs who practise in Australia, the generalisability of the findings is limited. Similarly, the number of participants from very remote areas was limited to four. Finally, data were not collected on participants' reasons 
for their selected patient management strategy. Despite these limitations, the results from this study reveal an important need to examine how patient outcomes are affected by the ways GPs respond to patients' cancer symptoms.

\section{Comparison with other literature}

Although the findings from this study may cause concern, the study is limited by the use of videovignettes, which prevented participants from interacting with the patient or their families. Such interactions may increase the prospect of referral. ${ }^{21}$ Research also suggests that a cancer diagnosis can be missed where there are: atypical presentations, non-specific presentations, very low prevalence rates, comorbidities and/or perceptual features. ${ }^{22}$ All cases in this study were typical and devoid of distracting features. Furthermore, participants were more inclined to manage the patient with investigations or a referral when using the interactive referral pro forma. As the pro forma required detailed patient information, participants may have been prompted to request additional evidence-like that of a pathology reportbefore referring the patient to a specialist. The risk in this case is of false negative investigation findings. Furthermore, a recent report on delayed cancer diagnoses noted a 'lack of reporting culture in primary care compared with acute hospitals... [As such] any analysis will show only a small proportion of incidents in primary care, and from general practice in particular'. ${ }^{23}$ This may explain the limited literature on potential delays to cancer diagnosis within primary care. The data presented here suggest a risk of delay. The review also concluded that some of the factors that contribute to practitioner delay included: symptom misattribution and/or no examination or investigation of malignancy. The data presented in this paper support these conclusions.

\section{Implications for clinicians and policymakers}

Results from this study suggest that some patients may receive a delayed cancer diagnosis, even when they present with typical cancer symptoms to a GP who can access relevant diagnostic tests. There was limited evidence that appropriate tests would be ordered, and a significant proportion of cases were not immediately referred for further investigation or specialist opinion. Therefore, better cancer outcomes may not be solely explained by GP access to investigations, but rather to other factors that were beyond the scope of this study. These may include expedient access to specialists via the private healthcare sector or different systems of care.

\section{Future directions}

Research is required to understand how GPs filter and use clinical information to determine the management of patients who present with cancer symptoms. Research is also required to identify efficient and effective referral pathways for these patients as they traverse the health system and progress along the care continuum.

\section{CONCLUSION}

Patients may receive a delayed cancer diagnosis, even when they present with typical cancer symptoms to a GP who can access relevant diagnostic tests. Although this may be partly improved through improved access to diagnostic tests, there are likely to be additional elements that influence the ways in which potential cancer symptoms are identified and managed within the context of primary care.

Acknowledgements The authors would like to gratefully acknowledge the contribution of the GP participants.

Contributors MJ conceived the study. VP undertook data collection. XM took primary responsibility for data analyses. $C O$ led the write-up. PM and $A D$ provided academic guidance. All authors contributed to the writing and preparation of this manuscript.

Funding This work was supported by the Western Australian Department of Health grant number not applicable.

Competing interests None declared.

Ethics approval Curtin University Human Research Ethics Committee (RD-14-11). All participants provided informed consent.

Provenance and peer review Not commissioned; externally peer reviewed.

Data sharing statement The technical appendix, statistical code and data set are available from the authors.

Open Access This is an Open Access article distributed in accordance with the Creative Commons Attribution Non Commercial (CC BY-NC 4.0) license, which permits others to distribute, remix, adapt, build upon this work noncommercially, and license their derivative works on different terms, provided the original work is properly cited and the use is non-commercial. See: http:// creativecommons.org/licenses/by-nc/4.0/

\section{REFERENCES}

1. Mitchell GK. The role of general practice in cancer care. Aust Fam Physician 2008;37:698-702.

2. Croft $P$, Porcheret M, Peat G. Managing osteoarthritis in primary care: the GP as public health physician and surgical gatekeeper. Br J Gen Pract 2011;61:485-6.

3. Health Workforce Australia. Doctors in focus. Adelaide, SA: Health Workforce Australia, 2012.

4. Department of Health (United Kingdom). Direct Access to Diagnostic Tests for Cancer. Best Practice Referral Pathways for General Practitioners. April 2012. https://www.gov.uk/government/uploads/ system/uploads/attachment_data/file/216503/dh_133511.pdf (accessed 9 Mar 2015).

5. Rubin G, Vedsted P, Emery J. Improving cancer outcomes: better access to diagnostics in primary care could be critical. $\mathrm{Br} J$ Gen Pract 2011;61:317-18.

6. Barraclough $\mathrm{K}$. The predictive value of cancer symptoms in primary care. Br J Gen Pract 2010;60:639-40.

7. Smith C. Urgent suspected cancer referrals from general practice. Br J Gen Pract 2012;62:14.

8. Vedsted P, Hansen RP, Bro F. General practice and early cancer diagnosis. Ugeskr Laeger 2011;173:1712-15.

9. Brown S, Castelli M, Hunter DJ, et al. How might healthcare systems influence speed of cancer diagnosis: a narrative review. Soc Sci Med 2014;116:56-63.

10. Mansell G, Shapley M, Jordan JL, et al. Interventions to reduce primary care delay in cancer referral: a systematic review. $\mathrm{Br} J$ Gen Pract 2011;61:e821-e35.

11. Shapley M, Mansell G, Jordan JL, et al. Positive predictive values of $\geq 5 \%$ in primary care for cancer: systematic review. $\mathrm{Br} J$ Gen Pract 2010;60:e366-e77. 
12. Jiwa $M$, Meng $R$, Magin $P$, et al. Impact of referral letters on scheduling of hospital appointments: a randomised control trial. Br J Gen Pract 2014;64:e419-e25.

13. NICE (National Institute for Health and Clinical Excellence). Referral guidelines for suspected cancer. London: NICE (National Institute for Health and Clinical Excellence), Apr 2011. Report No.: Contract No.: 27.

14. Britt $\mathrm{H}$, Miller GC, Henderson J, et al. General practice activity in Australia 2011-12. Sydney, NSW: University of Sydney, 2012 GEP 31.

15. AlHW (Australian Institute of Health and Welfare). Medical workforce 2011. Canberra, ACT: AIHW (Australian Institute of Health and Welfare), 2013 HWL 49.

16. General Practice Education and Training Limited. Annual report. Canberra, ACT: General Practice Education and Training Limited, 2012.

17. PHCRIS (Primary Health Care Research \& Information Service). Fast facts: GP numbers in Australia, 1999-2000 to 2010-11 [Website]. Bedford Park, SA: PHCRIS (Primary Health Care
Research \& Information Service), 2013 (cited 29 May 2013). http:// www. phcris.org.au/fastfacts/fact.php?id=6775

18. MacLennan AH. HRT in difficult circumstances: are there any absolute contraindications? Climacteric 2011;14:409-17.

19. Heathcote KE, Armstrong BK. Disparities in cancer outcomes in regional and rural Australia. Cancer Forum 2007;31: 70-4.

20. Winkens R, Dinant GJ. Rational, cost effective use of investigations in clinical practice. BMJ 2002;324:783-5.

21. Corner J, Brindle L. The influence of social processes on the timing of cancer diagnosis: a research agenda. J Epidemiol Community Health 2011;65:477-82.

22. Kostopoulou O, Delaney BC, Munro CW. Diagnostic difficulty and error in primary care-a systematic review. Fam Pract 2008;25:400-13.

23. Delayed diagnosis of cancer. Thematic review. National Patient Safety Agency. Royal College of General Practitioners. UK. 2010 http://www.nrls.npsa.nhs.uk/resources/?Entryld45=69894 (accessed 23/06/2015) 